\title{
Fault Analysis Through Euclidean Distance Classifier in CSTR
}

\author{
Rishi Sarup Sharma ${ }^{1 *}$, Lillie Dewan ${ }^{1}$, Shantanu Chatterji ${ }^{2}$ \\ ${ }^{1}$ Department of Electrical Engineering, National Institute of Technology, Kurukshetra 136119, India \\ ${ }^{2}$ Guru Nanak Institute of Technology and Management, Hoshiarpur, Punjab, India
}

Corresponding Author Email: rishi.sarup@gmail.com

https://doi.org/10.18280/mmc_a.920102

Received: 5 July 2018

Accepted: 17 February 2019

\section{Keywords:}

continuous stirred tank reactor (CSTR),

Euclidean distance, fault, fault diagnosis

\begin{abstract}
In this paper, the experimental study has been carried out on CSTR in the presence of process faults which can possibly occur due to sudden and unexpected change in certain process parameters. The faults like change in flow rate and the change in agitator speed have been injected into the system individually. As a result, there is a change in the output of CSTR i.e. titration end point. For analysing the injected faults, the Euclidean distance classifier has been employed. Through the Euclidean distance classifier, the nature and magnitude of faults can be visualized. Moreover, while varying the speed of agitators, it has been observed that fault becomes prominent at high speed of each of the agitators. This correlates with the Euclidean distance results in which it is observed that in case the speed of agitators is high, the Euclidean distance is of a high value. This distance has been calculated for the various single faults, in which only a single parameter has been varied at a time. The findings of this research can be helpful for guiding the process operator regarding the severity of the faults.
\end{abstract}

\section{INTRODUCTION}

Present day control systems are increasingly becoming more complex and algorithms developed to achieve the control are getting more sophisticated. This has led to a growth in the demand for fault tolerance, which can be achieved through the fault detection, isolation and accommodation [1]. The industrial chemical processes, at present, have incorporated improved automation systems for improved stability. The recent years have witnessed the increased complexity of the chemical process plants. This has made mandatory the use of umpteen sensors. The sensors coupled with many logging devices are being used for measuring process signals. This has been done for making easier the task of decision making, for the purpose of monitoring [2-4]. A fault can be observed as a type of malfunction, encountered in a dynamic system which eventually results in an unacceptable abnormality in the performance of the system [1]. Fault diagnosis facilitates the precise estimation of the faulty operating conditions that are captured in real time. It can hence avoid (if not completely eradicate) the fault occurrence, which leads to departing of process path from nominal conditions. Faults are capable enough to impair the system performance, lead to degrading of the quality of product and this can lead to subsequent losses [5]. The system that incorporates the competency of detection, isolation, identification or classification of faults is known as a fault diagnosis system. The basic purpose behind diagnosing the faults is to generate the anomalies amid the nominal and faulty conditions. These anomalies arise out of the fault diagnosis procedure and are characterized as residuals [6]. The major difficulty observed in framing these models is the difficulties involved in obtaining accurate mathematical models [7]. For ensuring the process safety and reliability, there is a need of an early detection and isolation system [8].
The fault diagnosis approaches applicable to chemical processes can be largely classified into two categories: Modelfree techniques (that are based on data-driven techniques like statistical analysis, expert systems, fuzzy logic and neural networks) $[9,10]$ and model-based techniques that employ the observer-based methods [10-15].

During the ongoing operation in the chemical process, there are several faults that make the system safety-critical and lower the productivity. The occurrence of faults reduces the process efficiency of process (in terms of poor quality of finished product), at times posing hazard to the personnel, causing environmental pollution and damage to equipment, in certain cases. The faults that are critical in a chemical process are: -

1. Actuator faults- These faults manifest in the form of disruption in electrical power supply,

mal-operation of valves and pumps.

2. Process faults- These faults occur in the form of sudden and unexpected change in some of the process parameters, use of impure materials giving rise to unwanted reactions. These faults are injected into the system, in the present article.

3. Sensor faults- These faults include sudden activation of wrong sensors indicating false alarms.

Owing to the above, fault diagnosis as well as fault detection have become issues of crucial importance in the field. [16]

In this paper, the experimental study has been carried out on CSTR in the presence of process faults which can possibly occur due to sudden and unexpected change in certain process parameters. The faults like change in flow rate and the change in agitator speed have been injected into the system individually. Due to these faults, change in the output of CSTR i.e. titration end point, has been analysed. 


\section{EXPERIMENTAL SETUP}

The process that has been under consideration is a Cascade CSTR which is as shown in Figure 1. The figure represents continuous stirring, which has been done in order to mix the two liquids having a variable flow rate. The most preferred mode is the Continuous operation, which has been employed for many chemical processes. The reactant streams are fed in a continuous manner into the vessels and product streams are withdrawn from each of the vessels. The cascade CSTR engages the mixing of the reactants ethyl acetate and sodium hydroxide using phenolthalin as indicator, which has been contained in the tanks shown in Figure 1 below. The solution of ethyl acetate and sodium hydroxide has been first prepared and thereafter poured in the tanks 1 and 2 respectively. Soon thereafter, both these solutions get mixed and then the resultant solution flows into the first vessel (labelled as 5 in the diagram), as shown in Figure 1. This solution further passes on to the next subsequent vessel (labelled as 6) and resultant solution comes out of the last and final vessel (corresponding to label 7 in the diagram). After obtaining each successive observation, the volumes in both the tanks keep diminishing.

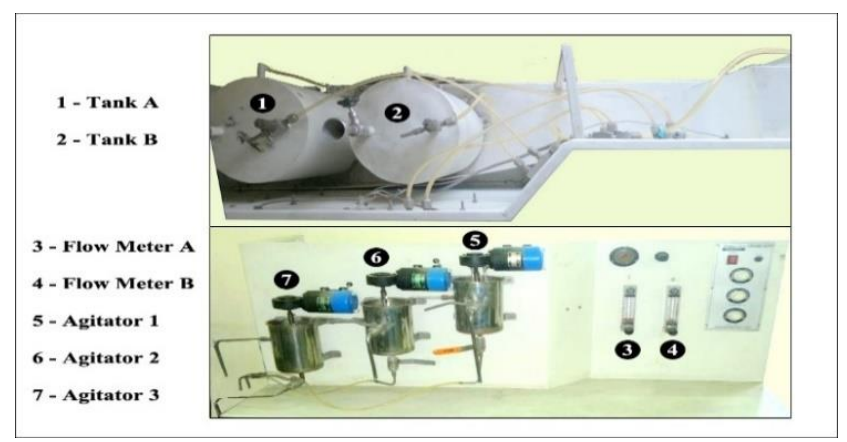

Figure 1. Experimental Set-up for CSTR

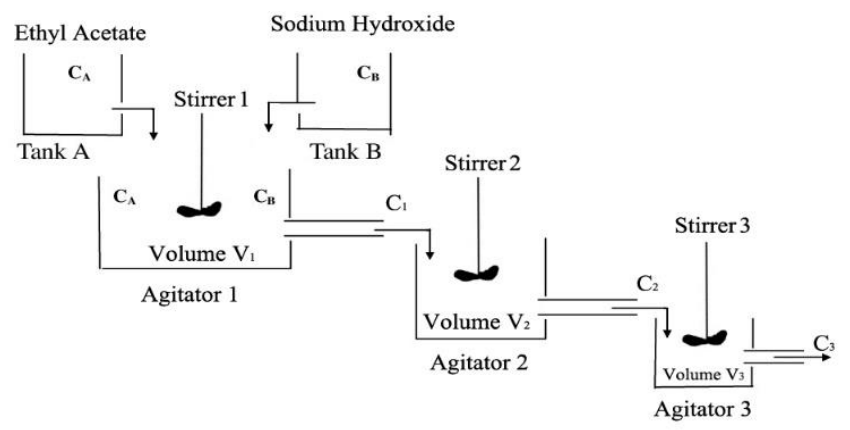

Figure 2. Schematic Representation of Laboratory CSTR

The above diagram shows the various linkages between the three agitators 1, 2 and 3 corresponding to the diagram of Figure 1. The reactants used in this experiment are ethylacetate and sodium-hydroxide respectively. The reactant of Tank A that contains ethyl-acetate which has a concentration of $\mathrm{C}_{\mathrm{A}}$ falls into the agitator 1 , having a volume $\mathrm{V}_{1}$. This reactant mixes with the reactant from Tank B i.e. sodium hydroxide and then the resultant concentration passes out of vessel 1 as $\mathrm{C}_{1}$. This solution, when passing through agitator 2 , after continuous stirring, comes out from vessel 2 at a reduced concentration $\mathrm{C}_{2}$. On similar lines, the solution then transfers to vessel 3 and after being stirred continuously, again comes out with a reduced concentration $\mathrm{C}_{3}$. The fact that the concentration of the solution keeps decreasing, can be verified from the values given in the Table 2 .

\subsection{Governing equations for volume flow}

The reaction kinetics of the reactants involves the saponification of ethyl-acetate, under the effect of alkaline conditions as per the Eq. (1) is:

\section{$\mathrm{NaOH}+\mathrm{CH}_{3} \mathrm{COOC}_{2} \mathrm{H}_{5} \longrightarrow \mathrm{CH}_{3} \mathrm{COONa}+\mathrm{C}_{2} \mathrm{H}_{5} \mathrm{OH}$}

There is no conservation in case of chemical components. In case a reaction takes place inside the system, for individual components the number of moles shall increase for reaction product. In case, the individual component happens to be a reactant, the number of moles shall decrease. Hence, as per the continuity equation: -

$$
\begin{gathered}
{\left[\begin{array}{c}
\text { Flow of moles of } A / B \text { component } \\
\text { into system }
\end{array}\right]-} \\
{\left[\begin{array}{c}
\text { Flow of moles of ith component } \\
\text { out of system }
\end{array}\right]+} \\
{\left[\begin{array}{c}
\text { Rate of moles formation of ith component } \\
\text { from chemical reactions } \\
\text { ofith component inside the system }
\end{array}\right]=}
\end{gathered}
$$

In Eq. (1), the units of the quantities are expressed in moles of component per unit time.

Assume the concentration of reactant $\mathrm{A}$ in the feed stream as $C_{A}$ (moles of $A$ per unit volume). The rate at which the reactant $\mathrm{A}$ is consumed (on a per unit volume basis) is in direct proportion to the instantaneous concentration of $\mathrm{A}$ in the tank. $\mathrm{F}$ stands for flow-rate of reactants and its unit is $\left(\mathrm{m}^{3} / \mathrm{min}\right)$.

For the component balance in reactant A (ethyl-acetate),

The flow of reactant $\mathrm{A}$ into system $=\mathrm{F} \mathrm{C}_{\mathrm{A} 0}$

Flow of reactant $\mathrm{A}$ out of system $=\mathrm{F} \mathrm{C}_{\mathrm{A}}$

Rate of formation of reactant $A$ from reaction $=-\mathrm{V} \mathrm{k} \mathrm{C}_{\mathrm{A}}$

Here k signifies the specific reaction rate.

The minus sign specifies that reactant $\mathrm{A}$ is being consumed, and not produced.

The above equations also hold for reactant $\mathrm{B}$ i.e. sodium hydroxide, that is placed in tank B

All the terms have the same units i.e. moles of reactant $A$ (or B) per unit time.

$$
\begin{aligned}
& \text { Time-rate of change of component } \mathrm{A}=\frac{d\left(V C_{A}\right)}{d t} \\
& \text { Time-rate of change of component } \mathrm{B}=\frac{d\left(V C_{B}\right)}{d t}
\end{aligned}
$$

Combining all the terms,

$$
\frac{d\left(V C_{A}\right)}{d t}+\frac{d\left(V C_{B}\right)}{d t}=\mathrm{F} \mathrm{C}_{1}-\mathrm{V}_{1} \mathrm{k} \mathrm{C}_{1}
$$

Here $\mathrm{C}_{\mathrm{A}}$ and $\mathrm{C}_{\mathrm{B}}$ relate with the reactant concentrations of $\mathrm{A}$ (ethyl acetate) and B (sodium hydroxide) which are stored in tanks A and B respectively. The equation for agitator 2 is given as

$$
\frac{d\left(V C_{2}\right)}{d t}=\mathrm{F}_{2} \mathrm{C}_{2}-\mathrm{V}_{2} \mathrm{k} \mathrm{C}_{2}
$$


The equation for agitator 3 is given as

$$
\frac{d\left(V C_{3}\right)}{d t}=\mathrm{F}_{3} \mathrm{C}_{3}-\mathrm{V}_{3} \mathrm{k} \mathrm{C}_{3}
$$

The rate of reaction is termed as specific-reaction-rate and is described in terms of the

$$
\text { Arrehenius equation as } \mathrm{k}_{\mathrm{n}}=\alpha \mathrm{e}^{-\mathrm{E} / \mathrm{RT}}{ }_{\mathrm{n}}
$$

where

$\mathrm{n}=1,2,3 \ldots$ etc. indicates the stage number as in Eq. (8)

$\mathrm{k}=$ specific-reaction-rate

$\alpha=$ pre-exponential-factor

$\mathrm{E}=$ activation energy that signifies the temperature dependence of the specific-reaction-rate

This implies that higher value of $E$ results in faster increase in $\mathrm{k}$ with increasing temperature. The units of $\mathrm{E}$ are $(\mathrm{Btu} / \mathrm{lb}$. $\mathrm{mol})$

$\mathrm{T}=$ Absolute temperature, which is expressed in degree Kelvin

$\mathrm{R}=$ Perfect gas constant $=1.99 \mathrm{Cal} / \mathrm{g} . \mathrm{mol} \mathrm{K}[17]$.

The following are the governing equations in CSTR for the reactants as follows: -

1. Reactant A (Ethyl Acetate) in Tank A, for moving to Agitator 1 is

$$
\text { Conversion rate, } \mathrm{X}_{\mathrm{A}}=\tau \mathrm{k}_{\mathrm{A}} /\left(1+\tau \mathrm{k}_{\mathrm{A}}\right)
$$

Here $\tau$ is average reactor resistance time and $\mathrm{k}_{\mathrm{A}}$ is reaction rate for component $\mathrm{A}$

2. Reactant B (Sodium Hydroxide) in Tank B for moving to Agitator 1 is

$$
\text { Conversion rate, } \mathrm{X}_{\mathrm{B}}=\tau \mathrm{k}_{\mathrm{B}} /\left(1+\tau \mathrm{k}_{\mathrm{B}}\right)
$$

Here $\tau$ is average reactor resistance time and $\mathrm{k}_{\mathrm{A}}$ is reaction rate for component $\mathrm{A}$

The reaction rate for moving to Agitator 1 is

3. Reaction rate,

$$
\mathrm{k}=\frac{C_{A 0 X_{A}}}{C_{A} C_{B}}
$$

The governing equations for the reaction (given in Eq. (1)) involve the combined conversion factor and the tine taken for the reaction, which are mentioned in Eqns. (12), (13) and (14) respectively.

The conversion factor, $\mathrm{X}$, is expressed in terms of reactant concentrations as

$$
1-\mathrm{X}=\frac{C_{A}}{C_{A 0}}=\frac{C_{B}}{C_{B 0}}
$$

The conversion factor can also be expressed as

$$
\mathrm{X}=1-\frac{-\left(1+2 \tau k C_{A}+\sqrt{1+4 \tau k C_{A}}\right.}{2 \tau k C_{A}}
$$

4. Resistance Time " $\tau$ "

It is the average time a volume element stays in the reactor and is denoted by" $\tau^{\prime \prime}$, and given as

$$
\tau=\frac{X}{k(1-X)\left(C_{B}-C_{A}\right)}
$$

The operational parameters and concentrations of the reactor and the constants are the physical parameters of the chemical reactor that have been used in the experiment. These are given in Table 1, Table 2 and Table 3, respectively.

Table 1. Reactor operating parameters

\begin{tabular}{|ccc|}
\hline S.No. & Parameter & Value \\
\hline 1. & Reaction constant $\tau$ & 0.2 \\
\hline 2. & Gain k & 0.5 \\
\hline 3. & Step size delta & 0.1 \\
\hline
\end{tabular}

Table 2. Reactor concentrations

\begin{tabular}{ccc}
\hline S.No. & Reactor & Concentration $\left(\mathbf{k m o l} / \mathbf{m}^{\mathbf{3}}\right)$ \\
\hline 1. & $\mathrm{Co}_{\mathrm{A}}$ & 1.8 \\
\hline 2. & $\mathrm{Co}_{\mathrm{B}}$ & 1.6 \\
\hline 3. & $\mathrm{C}_{1}$ & 0.4 \\
\hline 4. & $\mathrm{C}_{2}$ & 0.2 \\
\hline 5. & $\mathrm{C}_{3}$ & 0.1 \\
\hline
\end{tabular}

Table 3. Operating parameters of CSTR

\begin{tabular}{ccc}
\hline S.No. & Tank Parameters & Value \\
\hline 1. & Height & $200 \mathrm{~mm}$ \\
\hline 2. & Inside Diameter & $140 \mathrm{~mm}$ \\
\hline 3. & Volume & $3.078 \mathrm{Litres}$ \\
\hline 4. & $\begin{array}{c}\text { Height of Liquid in the } \\
\text { tank }\end{array}$ & $160 \mathrm{~mm}$ \\
\hline 5. & Working volume & 2.46 litres \\
\hline 6. & $\begin{array}{c}\text { Agitation speed } \\
\text { (variable) }\end{array}$ & $0-350 \mathrm{rpm}$ \\
\hline 7. & Fluid used & $\begin{array}{c}\text { Ethyl-acetate, sodium- } \\
\text { hydroxide }\end{array}$ \\
\hline 8. & Fluid-flow measurement & $0-19$ litres per hour \\
\hline & &
\end{tabular}

\section{EXPERIMENTAL OBSERVATIONS AND DISCUSSIONS}

When the reactor CSTR is working under nominal conditions, the flow rates of the reactants sodium hydroxide and ethyl acetate and the speed of agitators are the same. The variation is done in either flow rate or agitator speed and this subsequently results in a change in the experimental output. This change is then termed as "fault" present in the system. To monitor the behaviour of the system in the presence of faults i.e. intentional faults were introduced in the CSTR available in the laboratory. Experimental observations were taken under the following conditions: -

Case I: When no fault is present in the system which corresponds to Table 4.

Case II: When flow rate of sodium hydroxide / ethyl acetate is varying, governed by the flow meter $F_{A}$ and $F_{B}$ respectively and alongside the speed of any one of the agitators speed is varied while the other two agitators remain at constant speed. These are summarized in Table 5.

Table 4 takes into account the readings that have been taken under nominal conditions. The nominal conditions are those in which there is no change in any of the parameters of the chemical reactor. The parameters that can be varied are the 2 flow-rates (each of the ethyl-acetate and sodium-hydroxide solutions) and 3 agitator speeds (corresponding to each of the three vessels in which the solution is transferred after mixing). 
Table 4. Observations taken under ideal condition

\begin{tabular}{ccccc}
\hline Sr. No. & Flow Rate A $\left.\mathbf{~ m}^{\mathbf{3}} / \mathbf{h o u r}\right)$ & Flow Rate B $\left(\mathbf{m}^{\mathbf{3}} / \mathbf{h o u r}\right)$ & Time Elapsed (seconds) & Output at Normal Speed (ml.) \\
\hline 1 & 5 & 5 & 300 & 25.6 \\
\hline 2 & 5 & 5 & 500 & 25.8 \\
\hline 3 & 5 & 5 & 700 & 26.0 \\
\hline 4 & 5 & 5 & 900 & 26.1 \\
\hline 5 & 5 & 5 & 1100 & 26.0 \\
\hline 6 & 8 & 8 & 1300 & 25.9 \\
\hline 7 & 8 & 8 & 1500 & 25.8 \\
\hline 8 & 8 & 8 & 1700 & 25.7 \\
\hline 9 & 8 & 8 & 1900 & 25.9 \\
\hline 10 & 8 & 8 & 2100 & 25.8 \\
\hline 11 & 11 & 11 & 2300 & 26.0 \\
\hline 12 & 11 & 11 & 2500 & 26.0 \\
\hline 13 & 11 & 11 & 2700 & 26.1 \\
\hline 14 & 11 & 2900 & 26.2 \\
\hline 15 & 11 & 11 & 3100 & 26.0 \\
\hline 16 & 15 & 11 & 3300 & 25.9 \\
\hline 17 & 15 & 15 & 3500 & 25.7 \\
\hline 18 & 15 & 15 & 3700 & 25.5 \\
\hline 19 & 15 & 15 & 3900 & 25.6 \\
\hline 20 & 15 & 4100 & 25.8 \\
\hline 21 & 19 & 15 & 4300 & 25.7 \\
\hline 22 & 19 & 15 & 4500 & 25.9 \\
\hline 23 & 19 & 19 & 4700 & 26.0 \\
\hline 24 & 19 & 19 & 4900 & 26.1 \\
\hline 25 & 19 & 19 & 5100 & \\
\hline
\end{tabular}

Table 5. Summary of intentional faults

\begin{tabular}{ccccc}
\hline S.No. & Injected & & Description & Agitator-Speed \\
\cline { 3 - 5 } & Fault & Flow-Rate & Agitator-Speed & Stirrer 2 and 3 normal \\
\hline 1. & F1 & A changed & Stirrer 1 normal & Stirrer 2 and 3 normal \\
\hline 2. & F2 & B changed & Stirrer 1 normal & Stirrer 2 and 3 normal \\
\hline 3. & F3 & Same & Stirrer 1 low & Stirrer 2 and 3 normal \\
\hline 4. & F4 & Same & Stirrer 1 medium & Stirrer 2 and 3 normal \\
\hline 5. & F5 & Same & Stirrer 1 high & Stirrer 2 and 3 normal \\
\hline 6. & F6 & Same & Stirrer 2 low & Stirrer 2 and 3 normal \\
\hline 7. & F7 & Same & Stirrer 2 medium & Stirrer 2 and 3 normal \\
\hline 8. & F8 & Same & Stirrer 2 high & Stirrer 2 and 3 normal \\
\hline 9. & F9 & Same & Stirrer 3 low & Stirrer 2 and 3 normal \\
\hline 10. & F10 & Same & Stirrer 3 medium & Stirrer 2 and 3 normal
\end{tabular}

\section{EUCLIDEAN DISTANCE}

In the section that follows the Euclidean distance is used for comparing the effects of faults under different operating conditions. It is defined as the minimum distance between any two points. This distance is maintained as minimum when the points are aligned along a set of two parallel lines. These points lie at normal to these set of parallel lines [18]. For clustering, the data is divided into various groups. The clustering discriminates between a set of observation of one group from the other group. For measuring the dis-similarity between the different observations, a commonly used classifier is the Euclidean distance [19]. A cluster signifies a set of observations having similar properties. Clustering, hence, determines searching for the observation set having similar properties. For determining the cluster's distance from a data point is known as Euclidean distance and this has its grounds in the Pythagoras theorem [20].

Table 6. Case 1 - variation in flow-rate

\begin{tabular}{ccccccccc}
\hline S.No. & $\begin{array}{c}\text { Process } \\
\text { variable }\end{array}$ & $\begin{array}{c}\text { Fault } \\
\text { Type }\end{array}$ & $\begin{array}{c}\text { Relation of } \mathbf{F}_{\mathbf{A}} \\
\text { and } \mathbf{F}_{\mathbf{B}}\end{array}$ & Observation & $\begin{array}{c}\text { Agitator 1 } \\
\text { Speed }\end{array}$ & $\begin{array}{c}\text { Agitator 2 } \\
\text { Speed }\end{array}$ & $\begin{array}{c}\text { Agitator 3 } \\
\text { Speed }\end{array}$ & $\begin{array}{c}\text { Euclidean } \\
\text { Distance }\end{array}$ \\
\hline 1. & Flow- rate & $\begin{array}{c}\text { No } \\
\text { fault }\end{array}$ & Same & $\begin{array}{c}\text { Output } \\
\text { Unchanged }\end{array}$ & Normal & Normal & Normal & Nil \\
\hline 2. & Flow- rate & F1 & $\begin{array}{l}\text { FA changed } \\
F_{B} \text { constant }\end{array}$ & $\begin{array}{c}\text { Variation in } \\
\text { output }\end{array}$ & Normal & Normal & Normal & 18.4543 \\
\hline 3. & Flow- rate & F2 & $\begin{array}{l}F_{B} \text { changed } \\
F_{A} \text { constant }\end{array}$ & $\begin{array}{c}\text { Variation in } \\
\text { output }\end{array}$ & Normal & Normal & Normal & 12.8087 \\
\hline
\end{tabular}


In Table 6, the outcome of single fault in terms of variation in flow-rates has been considered. In this case, the flow-rate of reactant A (ethyl acetate), is varied. The influence of the fault is expressed as a Euclidean distance value, which is substantial. The second case considers the variation in flow-rate in reactant B i.e. sodium hydroxide. The above table expresses that the effect of fault F1 on the system is greater than fault F2. From Table 6, it is noteworthy in both the cases, during the fault occurrence, the flow-rate variation makes the operating conditions to a faulty level, which is expressed in terms of Euclidean distance.

Table 7. Case 2- Variation in agitator 1 speed

\begin{tabular}{ccccccccc}
\hline S.No. & $\begin{array}{c}\text { Process } \\
\text { variable }\end{array}$ & $\begin{array}{c}\text { Fault } \\
\text { Type }\end{array}$ & $\begin{array}{c}\text { Relation of } \\
\text { FA and F }_{\text {B }}\end{array}$ & Observation & $\begin{array}{c}\text { Agitator 1 } \\
\text { Speed }\end{array}$ & $\begin{array}{c}\text { Agitator 2 } \\
\text { Speed }\end{array}$ & $\begin{array}{c}\text { Agitator 3 } \\
\text { Speed }\end{array}$ & $\begin{array}{c}\text { Euclidean } \\
\text { Distance }\end{array}$ \\
\hline 1. & Flow- rate & $\begin{array}{c}\text { No } \\
\text { fault }\end{array}$ & Same & $\begin{array}{c}\text { Output } \\
\text { Unchanged }\end{array}$ & Normal & Normal & Normal & Nil \\
\hline 2. & Flow- rate & F3 & Same & $\begin{array}{c}\text { Variation in } \\
\text { output }\end{array}$ & Low & Normal & Normal & 46.249 \\
\hline 3. & Flow- rate & F4 & Same & $\begin{array}{c}\text { Variation in } \\
\text { output }\end{array}$ & Medium & Normal & Normal & 21.4356 \\
\hline 4. & Flow- rate & F5 & Same & $\begin{array}{c}\text { Variation in } \\
\text { output }\end{array}$ & High & Normal & Normal & 75.8982 \\
\hline
\end{tabular}

Table 7 expresses the single-fault in which the variation is carried out in the speed of one of the Agitator 2 is varied from normal to low, medium and high. The Euclidean distance for fault F5, is the highest among the faults considered in the above category. Moreover, at low agitator speed, the Euclidean distance, becomes nearly double in value, for the cases obtained in the faults F1and F2. It can hence be concluded that the magnitude of Euclidean distance in fault F4 is less than half its value, which has been obtained in fault F3. This Table 7 shows that when there is variation in the speed of agitator 1, the effect of fault is more than the effect observed in case of change in flow-rate, taking the magnitude of Euclidean distance into account, in both the cases.

Table 8. Case 3- Variation in agitator 2 speed

\begin{tabular}{|c|c|c|c|c|c|c|c|c|}
\hline S.No. & $\begin{array}{l}\text { Process } \\
\text { variable }\end{array}$ & $\begin{array}{l}\text { Fault } \\
\text { Type }\end{array}$ & $\begin{array}{c}\text { Relation } \\
\text { of } \\
\mathrm{F}_{\mathrm{A}} \text { and } \mathrm{F}_{\mathrm{B}}\end{array}$ & Observation & $\begin{array}{c}\text { Agitator } \\
1 \\
\text { Speed } \\
\end{array}$ & $\begin{array}{c}\text { Agitator } \\
2 \\
\text { Speed } \\
\end{array}$ & $\begin{array}{c}\text { Agitator } \\
3 \\
\text { Speed } \\
\end{array}$ & $\begin{array}{c}\text { Euclidean } \\
\text { Distance }\end{array}$ \\
\hline 1. & Flow- rate & No fault & Same & $\begin{array}{c}\text { Output } \\
\text { Unchanged }\end{array}$ & Normal & Normal & Normal & Nil \\
\hline 2. & Flow-rate & F6 & Same & $\begin{array}{l}\text { Variation in } \\
\text { output }\end{array}$ & Normal & Low & Normal & 44.7282 \\
\hline 3. & Flow- rate & F7 & Same & $\begin{array}{l}\text { Variation in } \\
\text { output }\end{array}$ & Normal & Medium & Normal & 20.8655 \\
\hline 4. & Flow- rate & F8 & Same & $\begin{array}{c}\text { Variation in } \\
\text { output }\end{array}$ & Normal & High & Normal & 77.7993 \\
\hline
\end{tabular}

Table 8 takes into account the case in which the speed variation in agitator 2 is done from normal to low, medium and high speeds. Euclidean distance for fault F8, has been observed to as the highest among the faults (F6, F7 and F8), in this category. This table concludes that the magnitude of Euclidean distance for fault F7 is less than half of the value, with regard to fault F6. This table signifies that upon varying the speed of agitator 2, the fault effect (in terms of Euclidean distance) is close with regard to the effect of change in the speed of agitator 1, considering both the cases.
Table 9 discusses the speed variation of agitator 3 from normal to low, medium and high speeds. The Euclidean distance for fault F11, has been observed as the highest among the faults (F9, F10 and F11), in this category. Apart from this, the Euclidean distance, for fault F9 is the lowest observed distance, under the group of faults. The table also concludes that the Euclidean distance for fault F10 is less than half, with regard to, fault F9. This is characterized in the bar graph shown in Figure 3.

Table 9. Case 4- variation in agitator 3 speed

\begin{tabular}{ccccccccc}
\hline S.No. & $\begin{array}{c}\text { Process } \\
\text { variable }\end{array}$ & $\begin{array}{c}\text { Fault } \\
\text { Type }\end{array}$ & $\begin{array}{c}\text { Relation of } \mathbf{F}_{\mathbf{A}} \\
\text { and } \mathbf{F}_{\mathbf{B}}\end{array}$ & Observation & $\begin{array}{c}\text { Agitator } \\
\mathbf{1} \\
\text { Speed }\end{array}$ & $\begin{array}{c}\text { Agitator } \\
\mathbf{2} \\
\text { Speed }\end{array}$ & $\begin{array}{c}\text { Agitator } \\
\mathbf{3} \\
\text { Speed }\end{array}$ & $\begin{array}{c}\text { Euclidean } \\
\text { Distance }\end{array}$ \\
\hline 1. & Flow-rate & No fault & Same & $\begin{array}{c}\text { Output } \\
\text { Unchanged }\end{array}$ & Normal & Normal & Normal \\
\hline 2. & Flow-rate & F9 & Same & $\begin{array}{c}\text { Variation in } \\
\text { output }\end{array}$ & Normal & Normal & Low & 35.4404 \\
\hline 3. & Flow-rate & F10 & Same & $\begin{array}{c}\text { Variation in } \\
\text { output }\end{array}$ & Normal & Normal & Medium \\
\hline 4. & Flow-rate & F11 & Same & $\begin{array}{c}\text { Variation in } \\
\text { output }\end{array}$ & Normal & Normal & High & 93.43831 \\
\hline
\end{tabular}




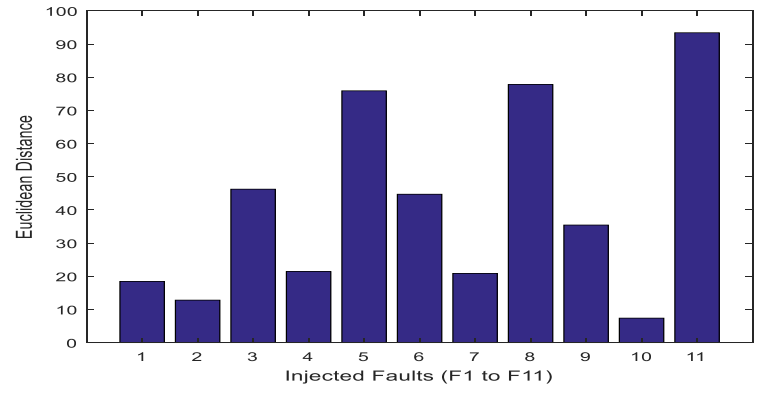

Figure 3. Plot of Euclidean distance for single faults

\section{CONCLUSION}

The paper deals with the experimental procedure, for the CSTR, for diagnosing faults. The experimental set-up examines the real-time aspects of a practical chemical process. The experiment, done on CSTR, explores the study of injecting faults, by way of variation in the operating conditions of the CSTR. The objective behind the study, made from Euclidean distance classifier, is to validate the results obtained through experimentation. In general, that Euclidean distance has been observed to be the highest for a particular class, when the agitator speed is varied from normal to high. The fault F10 is having the lowest magnitude of Euclidean distance. The magnitudes of the faults F3 and F6 are close to each other, since both these relate to low speeds of agitators 1 and 2 . The fault F11 has the highest value, among all the faults considered. The Euclidean distance for faults F5 and F8 is having comparable values, as both these correspond respectively to the high speeds of agitator 1 and 2. In the case of faults F4 and F7 the Euclidean distance is closer to each other, since the agitator speed is medium in case of agitators 1 and 2 respectively. The above discussion concludes that whenever there is a common factor in the operating conditions of the CSTR, subsequently the Euclidean distance, is observed as closer in magnitude to the values of the concerned faults. This fact corroborates with the observations, taken during the experimental procedure. The present work is aimed at providing useful information for supporting the operator in decision-making, while dealing with chemical reactor.

\section{REFERENCES}

[1] Frank, P.M. (1990). Fault diagnosis in dynamic systems using analytical and knowledge-based redundancy- a survey and some new results. Automatica, 26(3): 459474. https://doi.org/10.1016/0005-1098(90)90018-D

[2] Gomero, F.I., Melendez, J., Colomer, J. (2014). Process diagnosis based on qualitative trend similarities using a sequence matching algorithm. Journal of Process Control, 24(9):

http://dx.doi.org/10.1016/j.jprocont.2014.06.010

[3] Zhang, Z., Dong, F. (2014). Fault detection and diagnosis for missing data systems with three-time slice dynamic Bayesian network approach. Journal of Chemometrics and Intelligent Laboratory Systems, 138: 30-40. http://dx.doi.org/10.1016/j.chemolab.2014.07.009

[4] Yan, B., Wang, H., Wang, H. (2014). A novel approach to fault diagnosis for time-delay systems. Journal of Computers and Electrical Engg., 40: 2273-2284. http://dx.doi.org/10.1016/j.compeleceng.2014.08.009

[5] Marseguerra, M., Zio, E. (2009). Monte Carlo Simulation for model-based fault diagnosis in dynamic systems. Journal of Reliability Engineering and System Safety, 94: 180-86. https://doi.org/10.1016/j.ress.2008.02.013

[6] Calado, J.M.F., Korbicz, J., Patan, K., Paton, R.J., Sa Da Costa, J.M.G. (2001). Soft computing approaches to fault diagnosis for dynamic systems. European Journal of Control, $\quad$ 7(2-3): 248-286. https://doi.org/10.3166/ejc.7.248-286

[7] Lo, C.H., Wong, Y.K., Rad, A.B. (2004). Model-based fault diagnosis in continuous dynamic systems. ISA Transactions, 43(3): 459-475. https://doi.org/10.1016/S0019-0578(07)60161-X

[8] Isermann, R., Balle, P. (1997). Trends in the application of model-based fault detection and diagnosis of technical processes. Control Engineering Practice, 5(5): 709-719. https://doi.org/10.1016/S0967-0661(97)00053-1

[9] Isermann, R. (2005). Model-based fault detection and diagnosis- status and applications. Annual Reviews in Control, 29(1): 71-85. https://doi.org/10.1016/j.arcontrol.2004.12.002

[10] Caccavale, F., Pieeri, F., Iamarino, M., Tufano, V. (2009). An integrated approach to fault diagnosis for a class of chemical batch processes. Journal of Process Control, 19(5): $827-841$. https://doi.org/10.1016/j.jprocont.2008.11.003

[11] Gertler, J. (2005). Residual generation from principal component models for fault diagnosis in linear systems. Proceedings of the IEEE Conference on Intelligent Control, Limassol, Cyprus.

[12] Venkatasubrmanian, V., Rengaswamy, R., Yin, K., Kavuri, S.N. (2003). A review of process fault detection and diagnosis -Part I: Quantitative model-based methods. Computers and Chemical Engineering, 27(3): 293-311. https://doi.org/10.1016/S0098-1354(02)00160-6

[13] Venkatasubrmanian, V., Rengaswamy, R., Yin, K., Kavuri, S.N. (2003). A review of process fault detection and diagnosis -Part III: Process history-based methods. Computers and Chemical Engineering, 27(3): 327-346. https://doi.org/10.1016/S0098-1354(02)00162-X

[14] Ali, J.M., Hoang, N.H., Hussain, M.A., Dochain, D. (2015). Review and classification of recent observers applied in chemical process systems. Journal of Computers and Chemical Engineering, 76: 27-41. http://dx.doi.org/10.1016/j.compchemeng.2015.01.019

[15] Zhao, J., Wei, H., Guo, W., Zhang, K. (2014). Singularities in the identification of dynamic systems. Journal of Neuro-Computing, 104: 339-344. https://doi.org/10.1016/j.neucom.2014.03.004

[16] Gertler, J. (1997). Fault detection and isolation using parity relations. Journal of Control Engineering Practice, 5(5): 653-661. https://doi.org/10.1016/S09670661(97)00047-6

[17] Luyben, W.S. (1996). Process modelling, simulation and control for chemical engineers. Tata Mc Graw Hill International Edition ( $2^{\text {nd }}$ Edition $)$, pp. 39-83.

[18] Basseville, M., Nikiforov, I.V. (1993). Detection of Abrupt Changes: Theory and Applications. 123-130, Prentice Hall.

[19] Martinez, W.L., Martinez, A.R. (2002). Computational Statistics Handbook with MATLAB. CRC Press, 364374. 
[20] Cox, E. (2005). Fuzzy Modelling and Genetic Algorithms for Data Mining and Exploration. Morgan Kaufmann Publishers, Elsevier, 209-219.

\section{NOMENCLATURE}

$\mathrm{V}_{1}, \mathrm{~V}_{2}, \mathrm{~V}_{3} \quad$ volumes of the vessels in which the agitators are running, $\mathrm{m}^{3}$

$\mathrm{C}_{1}, \mathrm{C}_{2}, \mathrm{C}_{3} \quad$ final concentrations at the end of vessels, $\mathrm{kmol} / \mathrm{m}^{3}$

$\mathrm{Y}_{0}, \mathrm{Y}_{1}, \mathrm{Y}_{2}, \mathrm{Y}_{3}$

$F_{A}, F_{B}$

$\mathrm{k}_{\mathrm{A}}, \mathrm{k}_{\mathrm{B}}$

$\mathrm{k}$

$\tau$

$\mathrm{X}$

flow meters $\mathrm{A}$ and $\mathrm{B}, \mathrm{m}^{3} /$ hour

reaction rates of component $\mathrm{A}$ and $\mathrm{B}\left(\mathrm{min}^{-1}\right)$

gain (a constant) for equation (5), (6) and (7)

resitance time

conversion factor $\frac{d C_{a_{3}}}{d t}$

$\mathrm{T}=$

$\mathrm{R}=\mathrm{F}$

$\mathrm{C}_{\mathrm{A}}, \mathrm{C}_{\mathrm{B}}$

$\mathrm{Co}_{\mathrm{A}}, \mathrm{Co}_{\mathrm{B}}$

$\mathrm{n}=1,2,3, \ldots$, etc.

$\mathrm{k}$

$\alpha$

$\mathrm{E}=$ time rate of change of concentration inside the tank, $\mathrm{kmol} / \mathrm{m}^{3} / \mathrm{sec}$

Absolute temperature, which is expressed in degree Kelvin

Perfect gas constant $=1.99 \mathrm{Cal} / \mathrm{g} . \mathrm{mol} \mathrm{K}$

Concentartions of the reactants $\left(\mathrm{kmol} / \mathrm{m}^{3}\right)$

Intial concentarions of the reactants $\left(\mathrm{kmol} / \mathrm{m}^{3}\right)$

indicates the stage number, as denoted by equations (8)

specific-reaction-rate for equation (8) pre-exponential-factor for equation (8) activation energy that signifies the temperature dependence of the specificreaction-rate 